\begin{tabular}{|l|l|}
\hline Postprint version & 1.0 \\
\hline Journal website & http://www.sciencedirect.com/science/article/pii/S0020748912000478 \\
\hline Pubmed link & http://www.ncbi.nlm.nih.gov/pubmed/22369921 \\
\hline DOI & $10.1016 /$ j.ijnurstu.2012.02.002 \\
\hline
\end{tabular}

This is a NIVEL certified Post Print, more info at http://www.nivel.eu

\title{
Nurse prescribing of medicines in Western European and Anglo-Saxon countries: A survey on forces, conditions and jurisdictional control
}

\author{
MARIEKe KroEZEN ${ }^{\mathrm{A}}$, , ANNEKe L. FranCKE ${ }^{\mathrm{A}, \mathrm{B}}$, Peter P. GROENEWEGEN ${ }^{\mathrm{A}, \mathrm{C}}$, LISET VAN DiJK $^{\mathrm{A}}$ \\ ${ }^{a}$ NIVEL, Netherlands Institute for Health Services Research, PO Box 1568, 3500 BN Utrecht, The \\ Netherlands \\ ${ }^{\mathrm{b}}$ Department of Public and Occupational Health, EMGO Institute for Health and Care Research (EMGO+) \\ of VU University Medical Center, Amsterdam, The Netherlands \\ ${ }^{c}$ Department of Sociology and Department of Human Geography, Utrecht University, Utrecht, The \\ Netherlands
}

\begin{abstract}
Background: The number of Western European and Anglo-Saxon countries where nurses are legally allowed to prescribe medicines is growing. As the prescribing of medicines has traditionally been the task of the medical profession, nurse prescribing is changing the relationship between the medical and nursing professions.

Objectives: To gain more insight into the forces that led to the introduction of nurse prescribing of medicines in Western European and Anglo-Saxon countries, as well as into the legal, educational and organizational conditions under which nurses prescribe in these countries. Moreover, this study sought to determine which consequences nurse prescribing has for the division of jurisdictional control over prescribing between the nursing and medical professions.

Design: International survey.

Participants: An email survey was sent to 60 stakeholders of professional nursing or medical associations or government bodies, at national, state or provincial level across ten Western European and Anglo-Saxon countries, namely Australia, Canada, Finland, Ireland, the Netherlands, New Zealand, Spain, Sweden, the United Kingdom and the United States of America.

Methods: The survey addressed the reasons for the introduction of nurse prescribing and the conditions under which nurses are or will be prescribing medicines.

Results: The response rate was $65 \%(n=39)$. It was shown that a diversity of forces led to the introduction of nurse prescribing, and respondents from nursing and medical associations and government bodies cited different forces as being important for the introduction of nurse prescribing. Representatives of nurses' associations oftentimes emphasized the medication needs of patients living in remote geographical areas, while representatives of medical associations more often pointed to workforce shortages within the health care service. The conditions under which nurses prescribe medicines vary considerably, from countries where
\end{abstract}


nurses prescribe independently to countries in which prescribing by nurses is only allowed under strict conditions and the supervision of physicians.

Conclusions: Citing different forces as being important in the introduction of nurse prescribing can be conceived as a professional 'problem construction' in order to gain jurisdiction over the prescribing task. In most countries, nurses prescribe in a subordinate position and the jurisdiction over prescribing remains predominantly with the medical profession.

\section{What is already known about the topic?}

-The number of countries where nurses are legally allowed to prescribe medicines is growing, but actual nurse prescribing practices vary considerably, both between and within countries.

-Professions try to construct tasks in such a way that they can claim jurisdiction over them.

-Professions exist in an interdependent system in which they compete with each other about jurisdiction over certain tasks.

\section{What this paper adds}

- This study found that representatives of professional nursing associations, medical associations and government bodies cited different forces as being important for the introduction of nurse prescribing. This can be seen as professional problem construction in order to gain jurisdiction over the prescribing task.

-By applying Abbott's theory on the conditions under which nurses are prescribing, we conclude that various jurisdictional settlements between the nursing and medical profession concerning the prescribing task can be discerned. In most countries, jurisdiction remains predominantly with the medical profession.

\section{INTRODUCTION}

Nurse prescribing is a highly relevant issue in the current climate of cost containment and task substitution in health care. During the past decades, the number of countries where nurses are legally permitted to prescribe medication has grown considerably ( [Aarts and Koppel, 2009] and [0055]). However, even though the term 'nurse prescribing' suffices as a descriptor term (Jones, 2009), the actual practice it refers to varies considerably, both within countries and internationally ( [Buchan and Calman, 2004] and [Kroezen et al., 2011]). As a further growth of nurse prescribing can be anticipated, it is important to have a complete picture of nurse prescribing internationally, so as to inform future developments in this area.

Two crucial aspects in the organization of nurse prescribing are legislation and education (Jones, 1999), since these aspects determine who can prescribe and what can be prescribed. How legal and educational conditions translate into practice, is largely determined by the organizational conditions in place. Therefore, in describing nurse prescribing across Western European and Anglo-Saxon countries, this study focuses on the legal, educational and organizational conditions under which nurses prescribe.

\section{NURSE PRESCRIBING MODELS}

Despite the variety in nurse prescribing practices found internationally ( [Buchan and Calman, 2004], [Jones, 2009] and [Kroezen et al., 2011]), three general models of nurse prescribing are usually distinguished in the literature. These prescribing models are useful in structuring the variety of legal, educational and organizational conditions under which nurses are prescribing internationally. Moreover, these models were used to structure our survey.

The two models most often discussed in the literature are independent nurse prescribing and supplementary nurse prescribing. Legally permitted and qualified independent prescribers are responsible for the clinical assessment of a patient, the establishment of a diagnosis and decisions about the appropriateness of a medication, treatment or appliance, including the issuing of a prescription ( [Ball, 2009], [Buchan and Calman, 2004], [0040], [Van Ruth et al., 2008] and [Watterson et al., 2009]). Independent nurse prescribing usually takes place from a limited formulary - a list containing a limited and defined number of medicines that can be prescribed - or an open formulary. 
Supplementary nurse prescribing is defined as a partnership between an independent prescriber - usually a doctor - and a nurse. After the initial assessment and diagnosis of a patient's condition have been carried out by the independent prescriber, the nurse may prescribe from an open or limited formulary and will collaborate or consult with the independent prescriber before issuing the prescription, even though direct supervision is not required ( [Ball, 2009], [Buchan and Calman, 2004], [0050], [Hartley, 2003], [National Nursing and Nursing Education Taskforce, 2006] and [Watterson et al., 2009]). In the UK a third prescribing model is discerned, viz. community practitioner nurse prescribing, formerly known as district nurse and health visitor prescribing. Under this model district nurses and health visitors are allowed to prescribe independently, but only from their own specific formulary (Department of Health, 2010b).

\section{THEORETICAL BACKGROUND}

Traditionally, the task of prescribing medicines has been the sole domain of the medical profession ( [Buckley et al., 2006], [Fisher, 2010] and [Goundrey-Smith, 2008]). With the development of nurse prescribing, doctors are confronted with a 'rival' profession in this domain. This has consequences for the relationship between the medical and nursing profession, in which for example a perceived change in power balance can occur (Patel et al., 2009). After all, the introduction of nurse prescribing changes the division of jurisdiction between the medical and nursing profession, resulting in interprofessional competition over the prescribing task.

According to Abbott (1988), competition between professions over the jurisdiction over a task, in this case the prescribing of medicines, is shaped by various 'internal' and 'external' forces. Abbott characterizes internal forces as forces arising from within the professions themselves, and external forces as general social forces. An example of an external force that could possibly shape professional competition over prescribing rights is governmental striving for a more cost-effective healthcare system, whereas internal forces might be a shortage of doctors in the health workforce (Vrijhoef, 2002) or nurses' desire for more professional autonomy. Professions can use these internal and external forces to influence the outcomes of professional conflicts. Abbott states that by constructing problems in such a way that their knowledge is acknowledged as expert knowledge, professions can successfully claim jurisdiction over a task. Hence, in the case of nurse prescribing, naming certain internal or external forces can be seen as part of professional problem construction.

Professional competition can have various outcomes (Abbott, 1988). In general, all competing professions seek full jurisdiction over a task. Where nurses are able to independently prescribe medicines, with a fair range of prescribing freedom concerning medicine choice, both the nursing and medical profession hold equal and full jurisdiction over prescribing, according to Abbott's classification. However, this is an exceptional case. Because 'there are only so many full jurisdictions to go around', most professional conflicts result in so-called 'limited jurisdictional settlements' (Abbott, 1988). These are alternatives to the situation in which one or more professions hold full jurisdiction over a task. In a jurisdictional settlement, professions share the jurisdiction over a task, whereby jurisdictional control is to a greater or lesser extent equally distributed between the professions, depending on the type of jurisdictional settlement concerned. Abbott discerns several possible jurisdictional settlements, such as: subordination, whereby an incumbent profession controls the division of labor for one or more subordinate groups; client differentiation, in which different segments of a profession serve different client groups and; a division of labor, in which the jurisdiction over a certain task is divided between professions into 'functionally interdependent but structurally equal parts'. Supplementary prescribing can be considered a 'division of labor' in Abbott's terms, because of the clear delineation of areas of responsibility in the supplementary prescribing model.

\section{AIM AND RESEARCH QUESTIONS}

The aim of this study was to gain more insight into the forces that have led to the introduction of nurse prescribing and into the legal, educational and organizational conditions under which nurse prescribing of medicines is realized in Western European and Anglo-Saxon countries. Moreover, we aimed to investigate which consequences nurse prescribing has for the division of jurisdictional control between the nursing and medical professions. The following research questions were addressed:

1.As a result of which external and internal forces has nurse prescribing been initiated or already realized in Western European and Anglo-Saxon countries? 
2.Under which legal, educational and organizational conditions are nurses allowed to prescribe medicines within Western European and Anglo-Saxon countries?

3. Which jurisdictional settlements can be discerned between the medical and nursing professions concerning the task of prescribing medicines?

\section{METHODS}

\subsection{SAMPLE}

To answer our research questions, an email questionnaire was sent to representatives of national and regional professional nursing and medical associations and government representatives in ten Western European and Anglo-Saxon countries: Australia, Canada, Finland, Ireland, the Netherlands, New Zealand, Spain, Sweden, the United Kingdom and the United States of America. These countries were selected because they had realized or initiated nurse prescribing, as had been revealed in our earlier systematic review of the literature and from contact with relevant stakeholders (Kroezen et al., 2011). We considered nurse prescribing as 'being initiated' if at least a change in the law, or new legislation enabling nurses to prescribe medicines was in preparation, either at national, provincial or state level. As prescriptive authority in Australia, Canada and the USA is regulated at state, territorial or provincial level, we decided to select a purposive sample of three states, three provinces and five states respectively in these countries, and to invite representatives at state and provincial level to participate in our research as well.

To ensure that the most relevant professional associations were contacted, we used the membership lists of the International Council of Nurses (ICN) and World Medical Association (WMA) as points of departure. Professional associations and government bodies in the ten countries targeted were subsequently contacted by e-mail to obtain contact details of relevant representatives. In every country, state and province targeted, we strove to include at least one representative per type of association/government body in our study. Because of the variety in size and existing functions within professional associations and government departments, the decision as to who would be best suited to complete the survey was left up to the associations themselves. The majority of our respondents proved to be (vice) president, policy adviser or (chief) nursing officer within the organization in which they were employed.

\subsection{QUESTIONNAIRE}

The development of questions for the questionnaire was guided by the previous systematic literature review on nurse prescribing (Kroezen et al., 2011) and Abbott's theoretical model, which stresses the importance of internal and external forces in shaping professional competition over jurisdiction. Questions addressed the reasons for the introduction of nurse prescribing and the legal, educational and organizational conditions under which nurses are or will be prescribing medicines. It should be noted that we did not ask for respondents' visions or opinions on nurse prescribing, but only for the actual organization of nurse prescribing across countries.

Since some countries have introduced multiple forms of nurse prescribing, which are based on different legal, educational and organizational conditions, we structured our questionnaire according to the three general models of (nurse) prescribing usually distinguished in the literature. This means that respondents had to fill in one or more sections of the questionnaire, depending on how many nurse prescribing models were present in their country. To enhance content validity, the initial draft of the survey was reviewed by two experts on health law and policy (see Acknowledgments). Adjustments were subsequently made on the basis of their feedback.

The final questionnaire, which is available from the first author, consisted of a total of 105 questions, including skip patterns, divided in five sections. The first section asked for general background information regarding nurse prescribing, such as in what year nurse prescribing was introduced. The following three sections addressed the three general models of prescribing usually distinguished in the literature, viz. independent prescribing, supplementary prescribing and district nurse/health visitor prescribing. Each of these three sections asked for the legal, educational and organizational conditions under which nurses are or will be prescribing medicines. Which and how many of the three sections respondents had to complete, was dependent on the number of nurse prescribing models present in their country. The questionnaire ended with a section concerning the financial aspects of nurse prescribing. Questions included multiple-choice 
questions and free-response forms. To prevent confusion, possibly unknown terms such as 'supplementary prescribing' and 'controlled drugs' were briefly explained in the questionnaire.

\subsection{DATA COLLECTION AND ANALYSIS}

After we received the contact details of the 60 persons most suited to complete the questionnaire from the organizations contacted, a total of 60 surveys, accompanied by a cover letter, were sent by email. Up to two reminders were sent at three-weekly intervals to those who did not reply initially. Respondents were offered the option to complete the survey digitally and return their answers by email or return a hard copy of the questionnaire by fax. However, all responses were received by email $(\mathrm{n}=39)$. Subsequently, the majority of data were analyzed by comparing respondents' answers between countries, i.e. by comparing the legal, educational and organizational conditions under which nurses are prescribing between countries. Additionally, data concerning the reasons for the introduction of nurse prescribing were analyzed descriptively with calculations of response frequencies and percentages.

\section{RESULTS}

\subsection{DEMOGRAPHICS}

Of the 60 questionnaires that were mailed out, 39 were returned, yielding a response rate of $65 \%$. This is a relatively high response rate for a survey (Ray, 1999), and may reflect respondents' engagement in the subject. For every country, state and province, at least one survey was returned by a representative of one of the associations contacted. The response rates per country and type of organization are presented in Table 1.

\section{[TABLE 1]}

Even though our general response rate was relatively high, medical associations had a fairly low response rate (see Table 1). Representatives from two medical associations responded that they felt unqualified to accurately complete the questionnaire and one of them suggested alternative respondents. Health Canada (Federal Health Department) informed us that nurse prescribing falls under provincial and territorial jurisdiction and that we might wish to forward our survey to the provincial and territorial Ministries of Health. This advice was followed.

\subsection{Year of introduction of nurse prescribing}

Fig. 1 shows the timeline for the introduction of nurse prescribing across the Western European and Anglo-Saxon countries, provinces and states studied. It is noteworthy that nurse prescribing constitutes a relatively recent development in some countries, whereas in other countries, especially in some US states, nurse prescribing has been around for decades. Respondents sometimes showed minor deviations in the actual date of introduction. However, this might be explained by a frequently observed discrepancy between the point in time when a law is enacted or amended, and when it takes effect. ${ }^{1}$

\section{[FIGURE 1][TABLE 2]}

\subsection{Forces related to the introduction of nurse prescribing}

Abbott's theoretical model stresses the importance of internal and external forces in shaping professional competition over jurisdiction. Therefore, we asked respondents the following question: "As a result of which forces was legal nurse prescribing introduced within your country?” Respondents could choose more than one answer from the list provided in Table 2 and/or give a free-text response under the "other" heading. Respondents most often mentioned improving the quality of care and solving the workforce shortages within the health care service as forces which led to the introduction of nurse prescribing. For example, 12 of the 17 nursing associations that completed our questionnaire mentioned these forces as having led to the introduction of nurse prescribing within their respective country, state or province. "To improve patients' compliance with drug regimens” was mentioned least often.

Analysing representatives' answers at organizational level, we found differences between the three types of organizations. Representatives from nurses' associations (110/17) and government bodies (85/12) on average mentioned a higher number of forces compared to respondents from medical associations (16/7), 
see Table 2. They also think differently about the significance that certain forces have had in the introduction of nurse prescribing. While 9 out of 10 respondents from nurses' associations state that nurse prescribing was introduced to meet the medication needs of patients living in remote geographical areas, only 1 out of 3 representatives of government bodies and medical associations labeled this as a force that led to the introduction of nurse prescribing. The forces most often cited by representatives of medical associations were the workforce shortages within the health care service (6 out of 10). Government bodies mostly considered the introduction of nurse prescribing as an effort to improve the quality of care (8 out of 10 ). The forces cited by respondents under the answer category "other" mainly referred to forces already covered by the predetermined answer categories. In particular the recognition of nurses' skills and capacities, and offering patients quicker and better access to health care were again pointed out. However, answers given under the 'other' category were not classed under the existing multiple choice answer categories, as this would often imply double-counting.

\subsection{Conditions under which nurses are prescribing medicines}

\subsubsection{Legal conditions}

Before being allowed to start prescribing medicines, nurses in all Western European and Anglo-Saxon countries, provinces and states studied need to be formally registered. Most often, this involves registration with national nursing councils or health boards/councils, i.e. organizations that regulate, among others, the practice of nursing. However, where nurse prescribing is regulated at regional level, nurses generally register with state or provincial boards or colleges of nursing, such as in Canada and the USA. The exception is Australia, where nurses are always registered with the national regulatory body, even though nurse prescribing is regulated at state and territorial level.

All Western-European and Anglo-Saxon countries that have realized or initiated nurse prescribing have imposed legal restrictions on the categories of nurses that may prescribe medicines, what, how much and to whom they may prescribe, and whether they are allowed to do so on an independent basis or under the supervision of a physician. Nurses in almost all participating countries are allowed to prescribe on an independent basis. The exceptions are formed by the US states Georgia, Missouri and North Carolina, where nurses are only allowed to prescribe under the supervision of a physician. This form of prescribing, known as supplementary prescribing or prescribing in partnership with a physician, is found in a number of the other countries, provinces and states as well, albeit in addition to independent prescribing. As stated before, a third form of nurse prescribing is found in the UK, viz. community practitioner nurse prescribing (formerly known as district nurse/health visitor prescribing). This form of nurse prescribing for community practitioners differs from independent prescribing mainly in terms of the scope of prescriptive authority.

Prescribing rights in most countries are limited to certain categories of nurses. In the majority of countries, only nurse practitioners (NPs) have independent and/or supplementary prescribing rights, but in Ireland, Spain, the UK and South Australia all registered nurses can become nurse prescribers. In a number of other countries, only nurses with a particular specialization can obtain prescribing rights, such as in the Netherlands, where NPs will be granted independent prescribing rights, and supplementary prescribing rights will be granted to three groups of specialized nurses, namely diabetes, COPD and oncology nurses. Other regularly found limitations to nurses’ prescriptive authority are mostly age or distance related. In Finland for example, all children will be excluded from nurses prescriptive authority, whereas in a number of other countries NP speciality areas are narrowing the patient age groups for which NPs can prescribe. In Georgia and Missouri, where nurses have only supplementary prescriptive authority, mileage restrictions apply which designate that the nurse must be practising within a specified number of miles of her or his collaborating MD. In most countries though, independent and supplementary prescriptive authority are not limited to specific patient age groups or specific geographical areas.

Even though we found that nurses in most countries are (or will be) allowed to prescribe medicines on an independent basis, their scope of practice varies considerably, depending on whether or not protocols and/or formularies are in place and if so, how restrictive these are. Protocols or group protocols refer to written instructions for the supply and administration of named medicines in an identified clinical situation, whereas a formulary is a list containing a limited and defined number of medicines that can be prescribed. Clinical Management Plans (CMPs) are used in supplementary prescribing and relate to a named patient and to that patient's specific condition(s), while Collaborative Practice Agreements (CPAs) are mutually 
agreed upon plans between a nurse and one or more physicians that designate the scope of collaboration necessary to manage patient care.

It is clear from Table 3 that formularies are most often used in nurse prescribing, especially open formularies - general formularies applicable at national or regional level - and specific formularies related to nurses' specialization and scope of practice. Other means to restrict nurses' prescriptive authority such as (group) protocols, CMPs and restrictions contained in CPAs, are less often used in supplementary and especially independent nurse prescribing.

\section{[TABLE 3]}

In practically all countries that have granted nurses independent prescribing rights, nurses are allowed to prescribe prescription-only medicines (POMs), albeit often limited to those POMs that fall within their scope of practice. The exception is formed by Spain, where independent nurses prescribers are only allowed to prescribe pharmacist-only (P) and general sales list (GSL) medicines. Internationally, most supplementary prescribers are also allowed to prescribe POMs, but again only those medicines that fall within their scope of practice. Community practitioner nurse prescribers in the UK are allowed to prescribe a very limited number of POMs, some Ps and lots of GSLs.

In the majority of countries, independent and/or supplementary nurse prescribers can prescribe all kinds of prescriptions (both initial as well as an infinite number of repeat prescriptions), just like community practitioner nurse prescribers in the UK. However, this authority is sometimes limited to a certain time period. In Ireland for example, independent prescribers are allowed to prescribe repeat prescriptions up to one month following the patient assessment, and in Georgia and Missouri supplementary nurse prescribers can prescribe a 90 days supply and a 120 days supply respectively (for schedule III narcotics).

Independent nurse prescribers and supplementary nurse prescribers bear the same responsibilities for the treatment process of patients, in which the prescription of medicines forms just one element. However, supplementary nurse prescribers share their responsibilities more often with doctors and physicians. There are a few countries where the kind of responsibility - full or shared - is the same for independent and supplementary nurse prescribers. In Spain for example, independent and supplementary nurse prescribers are fully responsible for clinical decisions regarding the care of patients, but when it comes to the clinical assessment and diagnosis of patients and the prescribing of medicines, both groups of prescribers share their responsibility with physicians.

\subsubsection{Educational conditions}

Regarding the place that nurse prescribing training occupies within the various national education systems and the level at which it is provided, there are some differences between countries. In the vast majority of Western European and Anglo-Saxon countries, provinces and states studied, independent and supplementary prescribing courses form part of (Advanced) Nurse Practitioner education at Master degree level. However, in some countries prescribing training is provided through other educational programs. For example in Sweden prescribing training is part of the Primary Health Care Specialist Nursing programme, in the Netherlands supplementary prescribing training will initially be offered as a further education course at Bachelor level, whereas in Spain both independent and supplementary prescribing are taught as compulsory parts of the regular nursing degree (4 years) and as part of postgraduate Nursing Specialization programmes.

Furthermore, in some countries prescribing courses are offered on a stand-alone basis, i.e. they are offered apart from regular nursing curricula. In Ireland and the UK for example, where independent and supplementary

prescribing training are combined into a dual qualification, education programmes for nurse prescribing are offered at Bachelor level and on a stand-alone basis. The same is true for Finland, where prescribing training is offered as a stand-alone professional development training at Bachelor level. In the Australian states New South Wales and Victoria, the prescribing subjects from the Master's Degrees of (Advanced) Nursing Practice can also be followed as separate courses, e.g. by nurses who have already completed a Master's degree. And in the UK, training for community practitioner nurse prescribing can be completed as integral part of the Specialist Community Public Health Nursing programme, but also as a stand-alone course. 
Where prescribing courses are offered on a stand-alone basis, specific requirements have generally been established for nurses wishing to enter these courses. In Finland, Ireland and the UK, nurses, among others, need to have a minimum of 3 years clinical work experience (within the past 5 years) and support from their employer to be admitted to the separate prescribing course. In New South Wales and Victoria however, all interested nurses can take the prescribing subjects from the Masters Degrees as a separate course.

The content of training programmes for independent and supplementary nurse prescribing seems to be rather similar across Western European and Anglo-Saxon countries. Clinical pharmacology, clinical decision-making skills and diagnosis, consultation management, issues concerning concordance and adherence to medical treatment, legal, policy and ethical considerations concerning nurse prescribing, professional accountability and responsibility, and prescribing within a team-context are part of nurse prescribing training in most countries that have granted nurses independent and/or supplementary prescribing rights, irrespective of level of training and whether training is offered through regular nursing curricula or on a stand-alone basis. The possible influence of the pharmaceutical industry on prescribing is less often addressed in the prescribing courses. Only in Australia, Canada, Ireland, Spain, the UK and some states of the USA are nurses being educated on this subject. A small number of respondents mentioned additional course subjects, such as health research in Australia and complementary therapies in Ontario.

In almost all Western European and Anglo-Saxon countries studied, nurse independent and supplementary prescribing courses contain a practical component or internship. Only in Georgia, New South Wales, North Carolina and Sweden do nurses finish their training without completing a period of learning in practice. Supervision during the internship is most often provided by nursing educators and instructors and nurse supervisors, and somewhat less by medical supervisors. Although in Ireland and the UK medical supervision is a requirement.

\subsubsection{Organizational conditions}

Our earlier review of the nurse prescribing literature showed that organizational conditions and especially financial issues are scarcely addressed in the literature. Therefore, we incorporated a number of questions on financial issues in our questionnaire, among others concerning the financing of nurses' prescribing training. We found some differences in this regard. In New South Wales and Victoria, where prescribing subjects from Master's degrees can also be followed as separate courses, nurses have to pay the educational costs themselves. In Ireland, however, funding for separate nurse prescribing training is made available through the national government, whereas in Finland the national government and nurses' employers share the costs. In the UK, nurses and their employers share the training costs.

We also asked respondents whether prescriptions written by nurses are covered and if so, under which conditions and whether possible restrictions apply. Two respondents indicated they did not know the answer to this question and two respondents left the question blank. Moreover, we received contradictory answers for Alaska, Alberta, Australia, Finland, New Hampshire, North Carolina and Victoria. However, we note that in Georgia, the Netherlands, New Zealand and Sweden prescriptions written by nurses are covered by all insurance providers at the same rate as medicines prescribed by physicians. In other countries, provinces and states, the degree of reimbursement or coverage is influenced by characteristics of the nurse or policies of the insurer. For example in South Australia, only NPs working in rural and remote areas have access to the Pharmaceutical Benefits Scheme (PBS), whereas prescriptions written by NPs in metropolitan areas are not reimbursed by the PBS, except in acute settings.

An important issue for the nursing profession is whether the newly achieved prescribing task has resulted in higher payments for nurse prescribers. However, there is much ambiguity as to this issue. Seven respondents indicated they did not know whether nurses holding a prescribing qualification receive a higher financial compensation than comparable nurses without a prescribing qualification, and in another six states and countries, Alaska, Missouri, New Hampshire, New Zealand, North Carolina and South Australia, we found inconsistent answers to this question. What became clear, however, is that in most countries prescribing nurses do earn more than nurses without a prescribing qualification, but this is to be attributed to their general Advanced Nurse Practitioner qualification and not to their prescribing qualification as such.

\subsection{Jurisdictional settlements between the nursing and medical profession}

In order to answer research question 3 and determine which jurisdictional settlements can be discerned between the medical and nursing professions concerning the task of prescribing medicines, we will now 
discuss the conditions under which nurses are prescribing across Western European and Anglo-Saxon countries in the light of Abbott's theory on the division of labor (Abbott, 1988). Our results showed that almost all countries, states and provinces studied introduced independent nurse prescribing. Based on the formal definition of independent prescribing found in the literature, this would suggest that nurses and doctors in most Western European and Anglo-Saxon countries are sharing full and equal jurisdiction over the prescribing task. However, in many countries we found that such severe restrictions applied to nurses' independent prescriptive authority, via formularies of medicines and/or protocols, that it becomes impossible to speak of shared full jurisdictional control between the medical and nursing professions. These independent nurse prescribers mostly prescribe in a subordinate position to the medical profession.

Moreover, in some countries, nurses' prescriptive authority is limited by legislation or regulations to certain patient (age) groups. Not only does this constitute an even more restrictive form of subordinate jurisdiction, but it also involves elements of client differentiation. Only in the UK, where nurses prescribe independently from the entire British National Formulary for all medical conditions in their area of competence, does the level of nurses' autonomy prove sufficient for both the nursing and medical professions to be considered as holding equal and full jurisdiction over prescribing.

Supplementary prescribing is the single form of prescriptive authority for nurses in Georgia, Missouri and North Carolina, and a common form of prescribing in a number of other Western European and AngloSaxon countries. However, the conditions under which nurses prescribe in these countries do not always fully correspond with the formal definition of supplementary prescribing as provided in the introduction of this article. Nevertheless, these requirements do create a model of prescriptive authority highly comparable to supplementary prescribing, as doctors and nurses are (in)directly sharing the prescribing task. This means that where doctors and nurses are sharing the prescribing task, and both have particular responsibilities in the medical care of a patient, supplementary prescribing can be considered as a form of prescribing within a 'full division of labor', in Abbott's terms.

Hence, it is clear that the jurisdiction over the prescribing task in most countries, apart from the UK, remains predominantly with the medical profession.

\section{DISCUSSION}

In almost all countries involved in this study, (specific categories of) nurses are or will be allowed to prescribe on an independent basis, with the exception of three American states where nurses are only allowed to prescribe under the supervision of a physician. This form of prescribing is known as supplementary prescribing and can be found in a number of other countries as well, albeit in addition to independent prescribing. In the UK, a third main form of prescribing was distinguished, viz. community practitioner nurse prescribing. In the majority of Western European and Anglo-Saxon countries, only nurse practitioners can obtain prescriptive authority. In a number of countries nurses with a particular specialization can also acquire prescribing rights and in a few countries all registered nurses can become nurse prescribers. Most nurses prescribe from formularies, which are often to a greater or lesser extent restricted and/or tailored to specific conditions.

Preparation for prescribing occurs in the majority of Western European and Anglo-Saxon countries at Master level and through regular nursing curricula, most often a Master's Degree in Advanced Practice Nursing. However, in a few countries (e.g. Ireland and the UK) nurses are qualified via stand-alone courses and/or at Bachelor level. The content of training programmes appears to be fairly similar across all Western European and Anglo-Saxon countries, and often includes a period of learning in practice. However, in several countries, questions have been raised whether nurses are sufficiently prepared by current educational programmes and how knowledge will be maintained and further developed after their initial training ( [Banning, 2004], [Bullock and Manias, 2002] and [Wilhemsson and Foldevi, 2011]). In the light of the ongoing development of nurse prescribing internationally, further research should address these questions.

When it comes to the financial organization of nurse prescribing, we found differences between countries. In some countries (e.g. in some Australian states), separate prescribing courses for nurses are paid for by the nurses themselves, whereas in other countries costs are shared between the nurse, employer and/or government bodies. The degree of reimbursement for nurses' prescriptions also differed between countries, depending on characteristics of the nurse or policies of the insurer. What is most important perhaps, is that we received a relatively large number of contradictory answers to these financial questions and quite a 
number of respondents indicated not to know the answers. This is startling, as financial issues, especially related to reimbursement issues and education costs, are repeatedly mentioned as one of the main barriers to nurse prescribing ( [Kaas et al., 1998], [Kelly et al., 2010] and [McCann and Baker, 2002]). Many Western European and Anglo-Saxon countries, including those countries that are considering the introduction of nurse prescribing (such as Spain and The Netherlands), should pay attention to this - not only to make nurse prescribing practically feasible, but also to maintain the enthusiasm of nurses for taking up the prescribing task.

Applying Abbott's theory on the legal, educational and organizational conditions under which nurses are prescribing across countries, we conclude that the jurisdiction over the prescribing task in most countries, apart from the UK, remained predominantly with the medical profession. To elaborate on this conclusion, one must look at the forces that led to the introduction of nurse prescribing, as mentioned by representatives of different types of associations. As Abbott states, views on internal and external forces shape professional conflict over jurisdiction. Hence, where representatives of different organizations mention different forces as having been important in the introduction of nurse prescribing, this can be interpreted as a professional strategy to influence the division of jurisdiction over the prescribing task. In this study we indeed found that representatives of nursing associations, medical associations and government bodies cited different forces as being important in the introduction process of nurse prescribing. Respondents from medical associations almost only mentioned forces that made the nurse prescribing initiative a necessity, such as workforce shortages within the healthcare service, while respondents from nursing associations also frequently brought up reasons with less immediate urgency, such as the possibility to make better use of nurses' skills. By solely stressing the forces which make nurse prescribing an inevitable necessity, the medical profession may have strategically tried to retain as much jurisdictional control as possible, while the nursing profession may have aimed for the opposite result. Professions may in this way have tried to construct the task of prescribing medicines in their favor. This would be consistent with the finding that professional medical associations in most countries - in Australia, Spain, Sweden and the USA for example - have mainly opposed nurse prescribing ( [Ball, 2009], [Jones, 1999], [McCann and Baker, 2002], [Nilsson, 1994] and [Plonczynski et al., 2003]). Besides, this might be an explanation for the relatively lower response rate of medical associations in this survey (35\%) compared with government bodies (75\%) and nurses associations (85\%).

\section{LIMITATIONS}

The study has several limitations. First, the response rate for representatives of medical associations is lower (35\%) than that for government bodies (75\%) and nursing associations (85\%). Second, a small number of questions concerning the financial organization of nurse prescribing generated conflicting answers from respondents in the same country, state or province. This limits the degree of certainty with which we can make statements about financial aspects of nurse prescribing internationally. It should be noted that differing answers were found both in countries where nurse prescribing constitutes a relatively new phenomenon as well as in countries that had years of experience with nurse prescribing already. Hence, this discrepancy may indicate a serious problem, in that even stakeholders in the field of nurse prescribing are uncertain and/or have gaps in their knowledge about the financial organization of nurse prescribing, which is oftentimes difficult to understand. Thirdly, because our focus was on nurse prescribing, alternatives such as emergency provisions, were not discussed. Nevertheless, their possible presence across countries might have influenced the forces which led to the introduction of nurse prescribing and the conditions under which nurse prescribing was realized.

\section{CONCLUSION}

A diversity of external and internal forces led to the introduction of nurse prescribing internationally. Respondents from nurses associations, medical associations and government bodies cited different forces as being important for the introduction of nurse prescribing. This can be conceived as professional problem construction in order to gain jurisdiction over the prescribing task. The legal, educational and organizational conditions under which nurses prescribe medicines vary considerably between countries, from situations where nurses prescribe independently to situations in which prescribing by nurses is only allowed under strict conditions and the supervision of physicians. As a result, a variety of jurisdictional settlements between the nursing and medical professions concerning the task of prescribing can be discerned. In the 
UK, nurse prescribers share (full) jurisdiction with the medical profession, but in most countries, nurses prescribe in a subordinate position and the jurisdiction over prescribing remains predominantly with the medical profession.

\section{ACKNOWLEDGMENTS}

The authors wish to thank Aart Eliens (V\&VN - Dutch Nurses Association) and Diederik van Meersbergen (KNMG - Royal Dutch Medical Association) for their comments on the draft survey. Furthermore, our gratitude goes to all representatives and associations that participated in our survey: Christine Andrews, Ministry of Health, New Zealand; Lisa Ashley, Canadian Nurses Association; Fran Beall, Georgia Nurses Association; Jenny Beutel, Nursing \& Midwifery Office, South Australia Department of Health; Julianne Bryce \& Elizabeth Foley, Australian Nursing Federation; Elizabeth Dabars, Australian Nursing and Midwifery Federation - South Australia Branch; Nancy C. Davis, Alaska Nurses Association; Liza Edwards, Department of Health, New South Wales; Annette Fraser, Nursing \& Midwifery Office, Department of Health, Western Australia; Debra Funk, Missouri State Board of Nursing; Ana M. Giménez, Ministry of Health, Social Policy and Equality, Spain; Matt Griffiths, Royal College of Nursing, UK; Corry van den Hoed, Erasmus MC Sophia, the Netherlands; Per Johansson, Swedish Medical Association; Jill Kliethermes, Missouri Nurses Association; Ellen Leistra, Ministry of Health, Welfare and Sport, the Netherlands; Bobby Lowery, East Carolina University College of Nursing; Diederik van Meersbergen, Royal Dutch Medical Association; Lyle Mittelsteadt, Alberta Medical Association; Trish O’Hara, Australian Nursing Federation - Victorian Branch; Debbie Phillipchuck, College and Association of Registered Nurses of Alberta; Paul Robinson, UK Department of Health; Nancy Sanders, Alaska Board of Nursing; Helen Snell, Nurse Practitioner Advisory Committee, New Zealand; Marjukka VallimiesPatomäki, Ministry of Social Affairs and Health, Finland; Alberta Health and Wellness; Australian Medical Association; College of Nurses of Ontario; Department of Health, Victoria; Finnish Medical Association; Finnish Nurses Association; New Hampshire Board of Nursing; New Hampshire Medical Society; New Hampshire Nurse Practitioner Association; North Carolina Board of Nursing; Office of the Nursing and Midwifery Services Director, Ireland; Swedish Society of Nursing \& Swedish Association for District Nurses.Conflicts of interest

Liset van Dijk, PhD, received unrestricted grants from Astra Zeneca and Bristol-Myers Squib for a study not related to this manuscript.Funding

No funding was received for this study.Ethical approval

Not required.

\section{REFERENCES}

Aarts, J., Koppel, R., 2009. Implementation of computerized physician order entry in seven countries. Health Affairs 28, 404-414.

Abbott, A., 1988. The System of Professions: An Essay on the Division of Expert Labor. The University of Chicago Press, Chicago.

Ball, J., 2009. Implementing Nurse Prescribing: An Updated Review of Current Practice Internationally. International Council of Nurses, Geneve, $94 \mathrm{pp}$.

Banning, M., 2004. Nurse prescribing, nurse education and related research in the United Kingdom: a review of the literature. Nurse Education Today 24, 420-427.

Buchan, J., Calman, L., 2004. Implementing Nurse Prescribing: An Updated Review of Current Practice Internationally. International Council of Nurses, Geneve, 48 pp.

Buckley, P., Grime, J., Blenkinsopp, A., 2006. Inter- and intra-professional perspectives on non-medical prescribing in an NHS trust. Pharma-ceutical Journal 277, 394-398.

Bullock, S., Manias, E., 2002. The educational preparation of undergrad-uate nursing students in pharmacology: a survey of lecturers' percep-tions and experiences. Journal of Advanced Nursing 40, 716.

Department of Health, 2010a. Nurse prescribing FAQ. Available from: http://webarchive.nationalarchives.gov.uk/+/www.dh.gov.uk/en/ Healthcare/Medicinespharmacyandindustry/Prescriptions/TheNonMedicalPrescribingProgramme/Nurseprescribing/DH_4123003 (accessed 22.03.2010). Department of Health, 2010b. Nurse prescribing training and prepara-tion: extended formulary nurse prescribing and supplementary pre-scribing. Available from: http://www.dh.gov.uk/en/Healthcare/ 
Medicinespharmacyandindustry/Prescriptions/TheNon-Medical

PrescribingProgramme/Nurseprescribing/DH_4123001 (accessed 20.10.2010).

Department of Health, 2010c. Supplementary prescribing FAQ. Available from:

http://webarchive.nationalarchives.gov.uk/+/www.dh.gov.uk/

en/Healthcare/Medicinespharmacyandindustry/Prescriptions/ TheNon-

MedicalPrescribingProgramme/Supplementaryprescribing/ DH_4123034 (accessed: 23.03.2010).

Drennan, J., Naughton, C., Allen, D., Hyde, A., Felle, P., O'Boyle, K., Treacy, P., Butler, M., 2009. National Independent Evaluation of the Nurse and Midwife Prescribing Initiative. Dublin University College Dublin. Ref Type: Report.

Fisher, R., 2010. Nurse prescribing: a vehicle for improved collaboration, or a stumbling block to interprofessional working? International Journal of Nursing Practice 16, 579-585.

Goundrey-Smith, S., 2008. Electronic medicines management and non-medical prescribing. In: Hannah,

K.J., Ball, M.J. (Eds.), Principles of Electronic Prescribin. Springer-Verlag, London, pp. 119-136.

Hartley, J., 2003. Nurse prescribing the big picture. Nursing Times 99, 22- 25.

Jones, A., 2009. Nurse Prescribing in Mental Health. Wiley-Blackwell, Chichester.

Jones, M., 1999. Nurse Prescribing: Politics to Practice. Bailliere Tindall \& Royal College of Nursing, Edinburgh.

Kaas, M.J., Dahl, D., Dehn, D., Frank, K., 1998. Barriers to prescriptive practice for psychiatric/mental health clinical nurse specialists. Clinical Nurse Specialist 12, 200-204.

Kelly, A., Neale, J., Rollings, R., 2010. Barriers to extended nurse prescribing among practice nurses. Community Practitioner 83, 21-24.

Kroezen, M., Van Dijk, L., Francke, A.L., Groenewegen, P.P., 2011. Nurse prescribing of medicines in Western European and Anglo-Saxon countries: a systematic review of the literature. BMC Health Services Research 11 .

McCann, T.V., Baker, H., 2002. Community mental health nurses and authority to prescribe medications: the way forward? Journal of Psychiatric and Mental Health Nursing 9, 175-182.

National Nursing and Nursing Education Taskforce, 2006. National Nurse Prescribing Glossary. National Nursing \& Nursing Education Task-force, Melbourne.

Nilsson, M., 1994. Opposition to nurse-prescribing in Sweden. The Lancet 1077.

Patel, M.X., Robson, D., Rance, J., Ramirez, N.M., Memon, T.C., Bressing- ton, D., Gray, R., 2009. Attitudes regarding mental health nurse prescribing among psychiatrists and nurses: a cross-sectional ques-tionnaire study. International Journal of Nursing Studies 46, 1467- 1474.

Pharmaceutisch Weekblad, 2011. Finland: voorschrijvende verpleegkun-digen [Finland: prescribing nurses]. Available from: http:// www.pw.nl/nieuws/nieuwsberichten/finland-voorschrijvendeverpleegkundigen (accessed 24.01.2011).

Plonczynski, D., Oldenburg, N., Buck, M., 2003. The past, present and future of nurse prescribing in the United States. Nurse Prescribing 1, 170.

Ray, L., 1999. Measuring party orientations towards European integration: results from an expert survey. European Journal of Political Research 36, 283-306.

Van Ruth, L., Francke, A.L., Mistiaen, P., 2008. Effects of nurse prescribing of medication: a systematic review. Internet Journal of Healthcare Administration 5 lit.

Vrijhoef, H.J.M., 2002. Is It Justifiable to Treat Chronic Patients by Nurse Specialists? Evaluation of Effects on Quality of Care. Universitaire Pers Maastricht, Maastricht.

Watterson, A., Turner, F., Coull, A., Murray, I., 2009. An Evaluation of the Expansion of Nurse Prescribing in Scotland. Scottish Government Social Research, Edinburgh.

Wilhemsson, S., Foldevi, M., 2011. Exploring views on Swedish district nurses' prescribing - a focus group study in primary health care. Journal of Clinical Nursing 12, 643-650. 
Kroezen, M., Francke, A.L., Groenewegen, P.P., Dijk, L. van. Nurse prescribing of medicines in Western European and Anglo-Saxon countries: a survey on forces, conditions and jurisdictional control. International Journal of Nursing Studies: 2012, 49(8), 1002-1012

\section{TABLES AND FigURE}

Table 1

Response rates per country/state/province and type of organization.

\begin{tabular}{|c|c|c|c|c|}
\hline & $\begin{array}{l}\text { Nursing } \\
\text { organization }\end{array}$ & $\begin{array}{l}\text { Medical } \\
\text { organization }\end{array}$ & $\begin{array}{l}\text { Government } \\
\text { body }\end{array}$ & $\begin{array}{l}\text { Total \# of completed surveys } \\
\text { returned per country/state/province }\end{array}$ \\
\hline Alaska & 1 & - & 1 & 2 \\
\hline Alberta & 1 & 1 & 1 & 3 \\
\hline Australia & 1 & 1 & 1 & 3 \\
\hline Canada & 1 & - & - & 1 \\
\hline Finland & 1 & 1 & 1 & 3 \\
\hline Georgia & 1 & - & - & 1 \\
\hline Ireland & - & - & 1 & 1 \\
\hline Missouri & 1 & 1 & 1 & 3 \\
\hline The Netherlands & 1 & 1 & 1 & 3 \\
\hline New Hampshire & 1 & 1 & 1 & 3 \\
\hline New South Wales & - & - & 1 & 1 \\
\hline New Zealand & 1 & - & 1 & 2 \\
\hline North Carolina & 1 & - & 1 & 2 \\
\hline Ontario & 1 & - & - & 1 \\
\hline Québec & 1 & - & - & 1 \\
\hline South Australia & 1 & - & 1 & 2 \\
\hline Spain & - & - & 1 & 1 \\
\hline Sweden & 1 & 1 & - & 2 \\
\hline Victoria & 1 & - & 1 & 2 \\
\hline United Kingdom & 1 & - & 1 & 2 \\
\hline Total \# of completed surveys returned & 17 & 7 & 15 & 39 \\
\hline \# of surveys sent & 20 & 20 & 20 & 60 \\
\hline Response rate & $85 \%$ & $35 \%$ & $75 \%$ & $65 \%$ \\
\hline
\end{tabular}

Fig. 1. Timeline for the introduction of nurse prescribing.

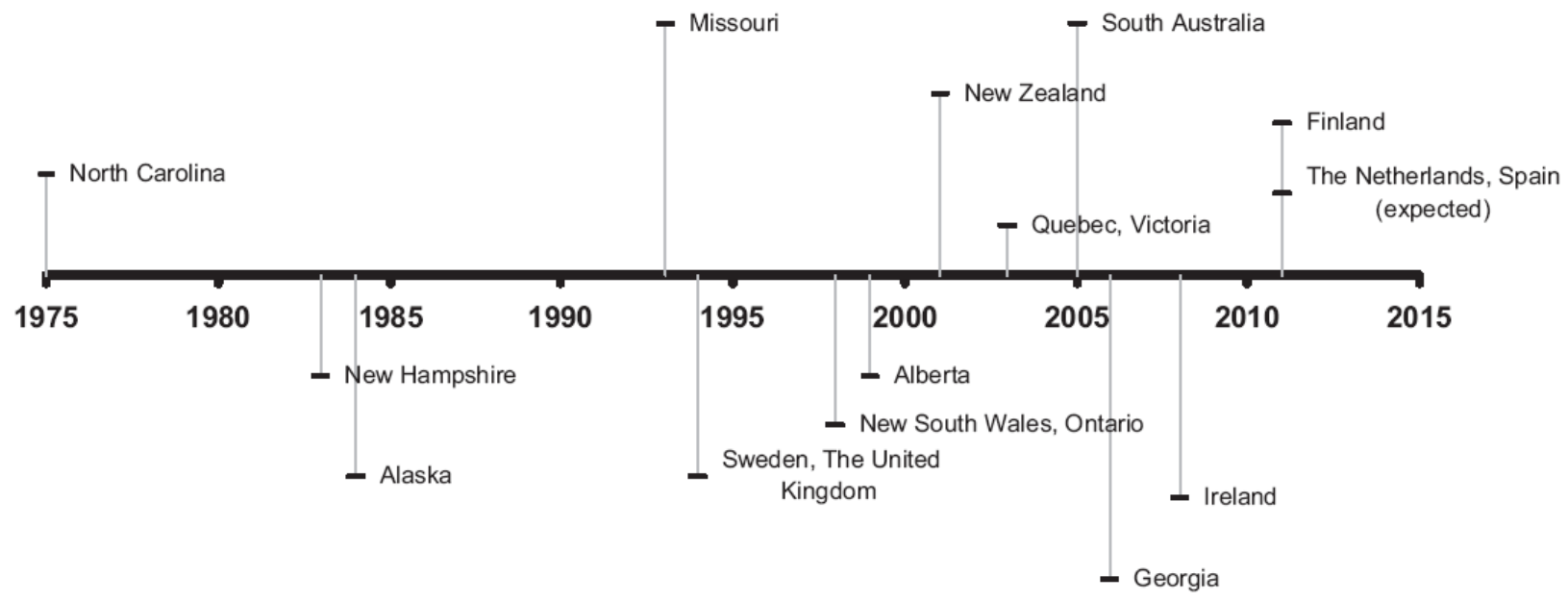


Kroezen, M., Francke, A.L., Groenewegen, P.P., Dijk, L. van. Nurse prescribing of medicines in Western 7 European and Anglo-Saxon countries: a survey on forces, conditions and jurisdictional control. International Journal of Nursing Studies: 2012, 49(8), 1002-1012

Table 2

Answers given to the question: 'As a result of which forces was legal nurse prescribing introduced within your country?' (multiple answers possible).

\begin{tabular}{|c|c|c|c|}
\hline & $\begin{array}{l}\text { Nurses } \\
\text { organization } \\
(n=17)\end{array}$ & $\begin{array}{l}\text { Medical } \\
\text { organization } \\
(n=7)\end{array}$ & $\begin{array}{l}\text { Government } \\
\text { body }(n=15)\end{array}$ \\
\hline To meet the medication needs of patients living in remote geographical areas & 15 & 2 & 5 \\
\hline To improve the quality of care & 12 & 2 & 12 \\
\hline As a solution to workforce shortages within the health care service & 12 & 4 & 10 \\
\hline To offer patients quicker/more efficient access to medicines & 12 & 2 & 10 \\
\hline To make better use of nurses' skills & 11 & 1 & 11 \\
\hline To increase the cost-effectiveness of the health care system & 8 & 0 & 8 \\
\hline To improve patient choice & 8 & 0 & 7 \\
\hline To modernize the health care system & 8 & 1 & 6 \\
\hline To increase team working within the health care service & 8 & 0 & 5 \\
\hline $\begin{array}{l}\text { To legalize standing prescribing practices by nurses } \\
\text { (i.e. where a doctor rubber-stamps a prescribing decision taken by a nurse) }\end{array}$ & 5 & 2 & 4 \\
\hline To reduce the workload of doctors and physicians & 4 & 1 & 3 \\
\hline To improve patients' compliance with drug regimens & 1 & 0 & 3 \\
\hline Other, please specify... & 6 & 1 & 1 \\
\hline Total \# of forces mentioned per type of organization & 110 & 16 & 85 \\
\hline Mean \# of forces mentioned per type of organization & 6.5 & 2.3 & 5.7 \\
\hline
\end{tabular}

Table 3

Use of formularies, group protocols, clinical management plans (CMPs) and Collaborative Practice Agreements (CPAs) in nurse prescribing.

\begin{tabular}{|c|c|c|c|c|c|c|}
\hline & \multicolumn{3}{|c|}{ Formularies } & \multirow[t]{2}{*}{ Group protocols } & \multirow[t]{2}{*}{ CPAs } & \multirow[t]{2}{*}{ CMPs } \\
\hline & Open & Specific & Individual & & & \\
\hline Alaska & IP & & & IP & & \\
\hline Alberta & IP & & & & & \\
\hline Finland & & IP, SP & & & & IP, SP \\
\hline Georgia & & & & & SP & \\
\hline Ireland & & & & & IP & \\
\hline Missouri & & & & SP & SP & \\
\hline The Netherlands & & IP, SP & & IP, SP & & \\
\hline New Hampshire & IP & & & & & \\
\hline New South Wales & & IP & & SP & & \\
\hline New Zealand & & IP & & IP & & \\
\hline North Carolina & & & & & SP & \\
\hline Ontario & IP & & & & & \\
\hline Québec & & IP & & & & \\
\hline South Australia & & & IP & & & \\
\hline Spain & & SP & & & & \\
\hline Sweden & & IP & & & & \\
\hline Victoria & & IP & & & & \\
\hline United Kingdom & IP, SP & $\mathrm{CP}$ & & & & SP \\
\hline
\end{tabular}

IP: independent prescribing; SP: supplementary prescribing; CP: community practitioner nurse prescribing. 